\title{
EXEMPLAR TRAINING AND A DERIVED TRANSFORMATION OF FUNCTION IN ACCORDANCE WITH SYMMETRY
}

\author{
YVONNE BARNES-HOLMES, DERMOT BARNES-HOLMES, \\ and BRYAN ROCHE \\ National University of Ireland Maynooth, Ireland
}

\author{
PAUL M. SMEETS \\ Leiden University, Holland
}

\begin{abstract}
The main purpose of the present study was to determine whether exemplar training would readily facilitate the transformation of function in accordance with symmetry. Sixteen children, aged between 4 and 5 years, were employed across four experiments (i.e., 4 children each in Experiments 1 to 4). In Experiment 1, subjects were first trained to name two actions and two objects by demonstrating listening, echoic, and tacting behaviors (e.g., hear name $\rightarrow$ point to object, hear name $\rightarrow$ say name, see object $\rightarrow$ say name, respectively). This name training served to establish that each of the subjects could clearly discriminate the experimental stimuli. Subjects were then trained in an action-object conditional discrimination using the previously named actions and objects (e.g., when the experimenter waved, choosing a toy car was reinforced, and when the experimenter clapped, choosing a doll was reinforced). Subjects were then reexposed to the name training, before exposure to a test for derived object-action symmetry relations (e.g., experimenter presents toy car $\rightarrow$ child waves and experimenter presents doll $\rightarrow$ child claps). Across subsequent sessions, a multiple-baseline design was used to introduce exemplar training (i.e., explicit symmetry training) for those subjects who failed the symmetry test. Experiment 2 replicated Experiment 1 , except that the name retraining (between the conditional discrimination training and symmetry test) was removed. Experiment 3 replicated Experiment 1, except that subjects were trained to tact all of the actions and objects during conditional discrimination training and symmetry testing. Experiment 4 replicated Experiment 1 , except that the trained and tested relations were reversed (i.e., train object-action, test action-object relations). Across the four experiments, 13 out of 16 subjects failed to show derived objectaction (Experiments 1-3) or action-object (Experiment 4) symmetry until they received explicit symmetry training. Overall, the data are consistent with Relational Frame Theory.
\end{abstract}

This work was conducted as part of a Ph.D. research program undertaken by Yvonne Barnes-Holmes, funded by the National University of Ireland, Maynooth. We thank Bill Mcllvane and one anonymous reviewer for their helpful and constructive comments on an earlier version of the current article. Correspondence should be directed to Yvonne BarnesHolmes at the Department of Psychology, National University of Ireland, Maynooth, Maynooth, Co. Kildare, Ireland. (E-mail: Yvonne.Barnes-Holmes@may.ie). 
In Sidman's (1971) seminal study of stimulus equivalence, a learningdisabled individual was trained and tested in a series of conditional discriminations. Specifically, the subject was trained to pick Stimulus B (picture of a car) in the presence of a Sample Stimulus A (dictated word "car"). In this way, a relation between the Stimuli A and B, or relation AB, was trained. An $A C$ relation was similarly trained when picking Stimulus C (printed word 'car') in the presence of Sample Stimulus A (dictated word "car") was reinforced. Following this type of explicit training in $A B$ and $A C$ relations, the subject picked Stimulus $C$ (printed word 'car') from a range of comparison stimuli (other printed words) in the presence of Sample Stimulus B (picture of a car). Thus a BC relation emerged without having been trained directly. Similarly, the subject chose Stimulus B from a range of comparisons when presented with Stimulus $C$ as a sample, thus demonstrating an untrained emergent $\mathrm{CB}$ relation. The derived relations of $B C$ and $C B$ in this instance constituted what Sidman has called a test for stimulus equivalence.

In the years that followed, Sidman conducted a range of related studies (see Sidman, 1994) and developed his mathematical set theory of the emergent behaviors that are typically observed in equivalence-type research. A core assumption of Sidman's account is that equivalence responding constitutes another basic stimulus function similar, for example, to reinforcement, discriminative control, or stimulus generalization. Other researchers, however, have been less than satisfied with this assumption. They have argued that equivalence may not be a newly discovered basic or fundamental behavioral process, but rather may be generated from already established basic behavioral processes. One theory that is most relevant here is Relational Frame Theory (RFT) (Hayes, Barnes-Holmes, \& Roche, in press).

According to RFT, arbitrarily applicable relational responding (or relational framing) is established, in large part, by an appropriate history of exemplar training (see Barnes, 1994, 1996; Barnes \& Holmes, 1991; Barnes \& Roche, 1996; Hayes, 1991, 1994; Hayes \& Hayes, 1989). Relational framing is defined as a generalized operant response class that is established through a history of reinforcement across exemplars, and once established, any stimulus event (regardless of form) may participate in a relational frame, given the relevant contextual cues. As described in many previous publications, the various patterns of derived relational responding are said to possess three properties: mutual entailment, combinatorial entailment, and transformation of stimulus function (e.g., Hayes, 1991, 1994; Hayes \& Hayes, 1989, 1992). Mutual entailment involves deriving a B-A relation from an explicitly reinforced $A$ $B$ relation. The simplest example of combinatorial entailment involves deriving $A-C$ and $C-A$ relations from explicitly reinforced $A-B$ and $B-C$ relations. A simple example of a transformation of function involves a derived relation between $\mathrm{A}$ and $\mathrm{B}$, and a transformation of function in $\mathrm{A}$ based on this relation. For example, if $A$ and $B$ participate in the mutually entailed relation of symmetry, and a punishing function is established for 
$B$, the previously neutral function of A may be transformed into a punishing function.

Relational Frame Theory has thus far generated a range of studies that could all be described loosely as demonstration research. Some of these studies developed experimental procedures for demonstrating complex patterns of derived relational responding in human adult subjects (e.g., Dymond \& Barnes, 1995, 1996; Roche \& Barnes, 1996, 1997; Steele \& Hayes, 1991; Wulfert \& Hayes, 1988), whereas others attempted to demonstrate a correlation between relational framing and specific natural language abilities (Barnes, Brown, Smeets \& Roche, 1995; Barnes, McCullagh, \& Keenan, 1990; Devany, Hayes, \& Nelson, 1986; Lipkens, Hayes, \& Hayes, 1993).

Although this research has provided evidence in favor of RFT, there have been no published studies concerned with how a repertoire of relational framing might be facilitated when it fails to emerge. For example, Devany et al. (1986) and Barnes et al. (1990) showed that equivalence was absent in language-disabled children, but no attempt was made to generate a repertoire of equivalencing using interventions suggested by RFT. In a similar vein, Lipkens et al. (1993) tracked the emergence of a simple repertoire of relational framing in a single child, but again no serious attempt was made to remediate deficits in relational framing (except for one instance of echoic training). The absence of any published RFT-based intervention research is rather surprising, given that RFT considers relational framing to be a type of generalized operant that is produced by a history of exemplar training. Surely a theory that emphasizes a history of reinforcement across exemplars, as the main basis for derived relational responding, should attempt to show that this type of history is indeed crucial for relational framing. The four experiments outlined subsequently constitute a first step towards addressing this issue.

The current study involved a nonmatching-to-sample procedure that allowed us to train and test for a derived transformation of functions in accordance with symmetry. We avoided using a conventional matching-tosample preparation because this procedure, it has been argued, may itself function as a contextual cue for symmetry and equivalence based on its use in preschool education exercises to teach picture-to-word equivalences. More informally, when a child is presented with a matching-to-sample task, this very format may be discriminative for matching things "that go together." (See Barnes, 1994, and Barnes \& Roche, 1996, for detailed discussions). Insofar as this is the case, matching-to-sample would not allow us to analyze the effects of exemplar training independently of the contextual functions provided by matching-to-sample itself.

The basic procedure we used involved training 4- to 5-year-old children to engage in listening, echoic, and tacting behaviors appropriate to particular actions and objects (i.e., name training). This name training served to establish that the children could clearly discriminate all of the actions and objects employed in the experiments. The children were then taught to pick one of two previously named objects conditional upon the previously named action of the experimenter (action-object training). During a subsequent test, 
the objects were presented to the subjects to determine whether they would show a transformation of function in accordance with symmetry. In effect, having been trained to pick Object $A$ when the experimenter waved, would the function of Object $\mathrm{A}$ be transformed in accordance with symmetry during the test, such that it would now control waving (i.e., object-action testing)? In Experiment 1 subjects were provided with name training (i.e., training in listening, echoic, and tacting behaviors), both before and after the actionobject training. Experiment 2 replicated Experiment 1, except that the name training was omitted after the action-object training. Experiment 3 replicated Experiment 1, except that subjects were also trained to tact all of the objects and actions during the action-object training and object-action testing (to ensure that the appropriate discriminations were maintained during the critical test phase). Experiment 4 replicated Experiment 1, except that the training and testing trial-types were reversed. In effect, subjects were trained to emit specific responses in the presence of particular objects (i.e., objectaction training) and were then tested for a transformation of functions in accordance with symmetry (i.e., action-object testing). The reader should note, that for ease of communication the term symmetry will sometimes be used instead of transformation of function in accordance with symmetry (see Barnes, 1996, for a detailed discussion of why the latter term is more accurate from a relational-frame perspective).

\section{GENERAL METHOD}

\section{Subjects}

Sixteen children, 8 male and 8 female, aged between 4 and 5 years old participated in the study. Each of the four experiments employed 4 children (see Table 1). They were enrolled in "Primary One" classes in two separate public schools in County Dublin, Ireland. The children were selected from

Table 1

Details of Subjects Who Participated in Each Experiment

\begin{tabular}{cccc}
\hline Experiment & Subject & Sex & Age (Yrs/Mths) \\
\hline 1 & 1 & Female & $5 / 2$ \\
& 2 & Female & $4 / 9$ \\
& 3 & Male & $4 / 3$ \\
2 & 4 & Male & $4 / 9$ \\
& 5 & Male & $5 / 1$ \\
& 6 & Male & $4 / 6$ \\
& 7 & Male & $4 / 11$ \\
3 & 8 & Female & $4 / 3$ \\
& 9 & Male & $4 / 6$ \\
& 10 & Female & $4 / 8$ \\
4 & 11 & Female & 5 \\
& 12 & Female & $4 / 5$ \\
& 13 & Female & $4 / 10$ \\
& 14 & Male & $5 / 1$ \\
& 15 & Female & $4 / 6$ \\
& 16 & Male & $4 / 4$ \\
\hline
\end{tabular}


volunteers following classroom announcements, and they were chosen on the basis that neither their mainstream school teachers nor parents had identified them as presenting a learning difficulty.

\section{Apparatus}

The experimental room contained one desk and two chairs. Subjects sat at the desk facing the experimenter. Experimental stimuli and actions employed in Session 1 of each experiment included a toy car and a doll, and waving and clapping. Henceforth, the stimuli are referred to using alphanumeric labels (e.g., toy car may be referred to as A1 and doll as A2). Experimental stimuli and actions employed in the other sessions of the experiments are described in Table 2. The allocation of stimuli to alphanumeric labels was counterbalanced across subjects; for instance, for 2 subjects $A 1$ was the car and A2 was the doll, whereas for the other 2 these labels were reversed. Subjects never saw these labels. Additional materials were also placed near the child. These included a tray with beads and an upright glass jar, showing a mark. Filling the glass jar to the level of the mark required 50 beads.

\section{Experimental Design}

The intervention in the current series of experiments involved explicit

Table 2

Stimuli, Actions, and Tacts Employed in Each Session for Experiments 1-4

\begin{tabular}{|c|c|c|c|}
\hline Session No. & Stimuli/Actions & Description of Stimuli/Actions & Correct Tact \\
\hline 1 & $\begin{array}{l}\text { A1 and A2 } \\
\text { Waving } \\
\text { Clapping }\end{array}$ & $\begin{array}{l}\text { Toy Doll: approx. } 4 \text { in. tall. } \\
\text { Toy Car: approx. } 4 \text { in. in length. } \\
\text { Waving hand or arm through air. } \\
\text { Clapping both hands together. }\end{array}$ & $\begin{array}{l}\text { "Doll" } \\
\text { "Car" } \\
\text { "Waving" } \\
\text { "Clapping" }\end{array}$ \\
\hline$\|$ & $\begin{array}{l}\text { B1 and B2 } \\
\text { Arms Out } \\
\text { Arms In }\end{array}$ & $\begin{array}{l}\text { Storybook: children's, approx. } 4 \times 4 \text { in. } \\
\text { Flower. plastic, approx. } 3 \text { in. in length. } \\
\text { Holding both arms out perpendicular to body. } \\
\text { Holding both arms at sides of body. }\end{array}$ & $\begin{array}{l}\text { "Book" } \\
\text { "Flower" } \\
\text { "Arms Out" } \\
\text { "Arms In" }\end{array}$ \\
\hline III & $\begin{array}{l}\text { C1 and C2 } \\
\text { Pulling Ear } \\
\text { Pulling Nose }\end{array}$ & $\begin{array}{l}\text { Toy Bear: approx. } 4 \text { in. tall. } \\
\text { Building Block: approx. } 2 \text { in. square. } \\
\text { Pulling either left or right ear with fingers. } \\
\text { Touching nose with fingers. }\end{array}$ & $\begin{array}{l}\text { "Bear" } \\
\text { "Block" } \\
\text { "Pulling Ear" } \\
\text { "Touching Nose" }\end{array}$ \\
\hline IV & $\begin{array}{l}\text { D1 and D2 } \\
\text { Rubbing Head } \\
\text { Scratching Tummy }\end{array}$ & $\begin{array}{l}\text { Cup: plastic, approx. } 4 \text { in. tall. } \\
\text { Shoe: children's, approx. } 5 \text { in. in length. } \\
\text { Rubbing the top of the head with hand. } \\
\text { Scratching tummy with fingers. }\end{array}$ & $\begin{array}{l}\text { "Cup" } \\
\text { "Shoe" } \\
\text { "Rubbing Head" } \\
\text { "Scratching Tummy" }\end{array}$ \\
\hline v & $\begin{array}{l}\text { E1 and E2 } \\
\text { Touching Feet } \\
\text { Flapping Arms }\end{array}$ & $\begin{array}{l}\text { Pencil: wooden, approx. } 6 \text { in. long. } \\
\text { Schoolbag: approx. } 12 \times 12 \text { in. } \\
\text { Touching both feet with fingers. } \\
\text { Flapping arms outward and inward from body. }\end{array}$ & $\begin{array}{l}\text { "Pencil" } \\
\text { "Bag" } \\
\text { "Touching Feet" } \\
\text { "Flapping Arms" }\end{array}$ \\
\hline $\begin{array}{r}V I \\
(F / U p)\end{array}$ & $\begin{array}{l}\text { F1 and F2 } \\
\text { Hands Behind Back } \\
\text { Hands Over Eyes }\end{array}$ & $\begin{array}{l}\text { Hat: woollen, approx. } 12 \text { in. round. } \\
\text { Plate: plastic, approx. } 6 \text { in. wide. } \\
\text { Placing both hands behind back. } \\
\text { Placing both hands over both eyes. }\end{array}$ & $\begin{array}{l}\text { "Hat" } \\
\text { "Plate" } \\
\text { "Behind Back" } \\
\text { "Over Eyes" }\end{array}$ \\
\hline
\end{tabular}


symmetry training across one or more exemplars. This training was introduced according to a multiple-baseline design across subjects in each of the four experiments. Assuming that subjects failed the test for a transformation of function in accordance with symmetry, the first subject in each experiment was introduced to the explicit symmetry training after the first failure, the second subject after the second failure, the third subject after the third failure, and the fourth subject after the fourth failure.

Interobserver reliability. Twenty-five percent of training and testing trials across all experiments were observed by an independent observer, who had no knowledge of experimental psychology. The observer could not see the experimenter's data sheet during the experimental sessions. Agreement between the observer's and the experimenter's recordings was $100 \%$.

\section{Experiment 1}

\section{Procedure}

Experimental sequence. Subjects completed all experimental procedures individually. They were exposed to between 1 and 6 sessions of training and testing. Each session consisted of between 4 and 5 phases, with each phase lasting between 5 and 30 minutes. Subjects were exposed to between 1 and 3 phases per day, with 5-minute breaks between phases (the children were allowed to play in an adjacent room during these breaks). Each child continued with the next phase, or with the first phase of the next session, on the next weekday (availability permitting). The follow-up session, however, was conducted approximately 2 months after the first sequence of training and testing. In Experiment 1, 1 subject required only one session of training and testing. The 3 remaining subjects required multiple sessions.

Programmed consequences. At the beginning of Session I, the experimenter placed the bead containers on the table and the subject was told that (a) he or she was going to play a game in which a bead would be awarded for each correct response, and (b) the beads could be exchanged for a preselected picture when the mark on the glass jar (50 beads) had been reached (Smeets, Barnes, \& Luciano, 1995). A correct response during all training trials was reinforced with the words "Yes, you are correct. Good girl/boy. Take a bead." Punishment during training trials consisted of the experimenter saying: "No, this is not right. No bead." No beads could be selected after an incorrect response had been emitted. No programmed consequences followed any test trial.

Session I: Phase 1. Name training. All subjects were individually trained in the naming of two gross motor activities, waving and clapping, and in the naming of two objects, A1 and A2. To ensure that all of the actions and objects could be readily discriminated, name training involved explicitly reinforcing appropriate listening, echoic, and tacting behaviors. For objects, this involved reinforcing choosing an object when given its name (listening), reinforcing uttering the name of the object when asked, for example, to "Say car" (echoic behavior), and reinforcing uttering the 
name of the object when asked "What is this?" (tacting). For actions, this involved reinforcing an action when asked to demonstrate it (listening), reinforcing repeating the name of the action in the presence of the name (echoic behavior), and reinforcing uttering the name of the action when asked, "What am I doing?" (tacting). The name training (Phase 1) and retraining (Phase 3 ), therefore, consisted of 12 different trial-types, 4 listening, 4 tacting, and 4 echoic trials with respect to the two actions and the two objects.

Six of these trial-types involved training listening, echoic, and tacting behaviors with respect to waving and clapping. These trials were presented randomly for each subject and were as follows. During a wave-listening trial, the child was asked "Show me waving." A correct listening response consisted of the child demonstrating the waving action. During a waveechoic training trial, the experimenter said to the child, "Can you say 'waving'?" A correct echoic response consisted of the child repeating the word "waving" back to the experimenter within $3 \mathrm{~s}$. During a wave-tacting trial, the experimenter waved her arm in a left-right-left sequence at the child whilst asking "What am I doing?" A correct tact response consisted of the child saying "waving" or any phrase containing the word "waving."

Listening, echoic, and tacting trial-types were similarly conducted for the clapping action. That is, on a clap-listening trial the child was asked "Show me clapping," on a clap-echoic trial, the child was asked "Can you say clapping?", and on a clap-tacting trial the experimenter clapped her hands and asked concurrently "What am I doing?" Correct responses again consisted of the child emitting the clapping action (for listening), saying "clapping" (for echoing and tacting) or a phrase containing this word, respectively.

The remaining six trial-types involved training listening, echoic, and tacting behaviors with respect to two objects, and these trials were conducted as follows. On an object-listening trial, the Stimulus A1 was placed on the table with A2, and the child was asked, for example, "Can you point to (A1) (e.g., the car)?" A correct listening response involved the child pointing to the correct object (i.e., A1). On an object-echoic trial, the experimenter asked, for example, "Can you say 'car'?" A correct echoic response here consisted of the child repeating the word "car" or any phrase containing this word. On an object-tacting trial, the experimenter pointed to A1, for example, and the child was asked "What is this?" A correct tact response involved the child saying the appropriate name (e.g., "car") or any such phrase containing this word. The same procedure was adopted for training listening, echoic, and tacting behaviors with respect to Stimulus A2. Again, correct responses consisted of the child pointing to the correct object (on listening trials), repeating the name of A2 (on echoic trials), or providing the correct tact for A2 (on tacting trials). Programmed consequences were provided on all trials. The 12 trial-types were presented randomly, without replacement, in blocks of 12 trials until a subject completed an entire block without error.

Phase 2. Action-object training. Following the name training, subjects 
were introduced to the action-object conditional discrimination training. This training consisted of two trial-types. These were presented in a quasi-random order, with each trial-type presented four times in each block of eight trials. Stimuli A1 and A2 were placed horizontally across the table from one another (the left-right positions of these stimuli were randomized across trials). The instructions were as follows: "When I wave/clap at you, I want you to pick (e.g., the car) (A1) or (e.g., the doll) (A2). I will tell you if you have chosen the right or wrong one." The same procedure was used for all subsequent training trials, except that the verbal instruction was omitted after the first four trials. Selecting A1 in the presence of the experimenter waving (wave-A1) and $A 2$ in the presence of the experimenter clapping (clap-A2) were reinforced. When subjects responded correctly on eight consecutive trials, it was assumed that the action-object relations were established.

Phase 3. Name retraining. Following the explicit training of the two action-object relations, each child was reexposed to Phase 1 to ensure that the naming discriminations were still intact.

Phase 4. Test for derived object-action relations. The test for derived object-action relations consisted of two trial-types, each of which was presented four times in a quasi-random order across a block of eight trials. Stimulus A1 (or A2) was placed in the center of the table. The experimenter remained silent and looked directly down at the near edge of the table, so that the subject could not see the experimenter's face. The experimenter only looked up when the child initiated a response. A 10-s interval was allowed for the child to respond (i.e., clap or wave). If the subject failed to clap or wave during this interval, the trial was recorded as incorrect (this rarely occurred; see General Discussion). Because this was a test phase, no feedback was given. Stimulus A2 (or A1) was then presented, and the procedure was repeated appropriately. If eight consecutively correct responses (A1-wave and A2-clap) were demonstrated, it was assumed that the derived object-action relations were established, and the subject's participation in the experiment was terminated for the time being. If, however, eight consecutively correct trials were not achieved, the multiple-baseline design required that Subjects 2, 3, and 4 be immediately reexposed to Phase 2 (i.e., the action-object training) before proceeding to the next session (in fact, all subjects in the current study who were reexposed to Phase 2, always completed this training in the minimum number of trials). If Subject 1 failed the test, however, she was exposed immediately to Phase 5.

Phase 5. Explicit object-action (symmetry) training. The test procedure outlined above for the derived object-action relations was repeated, but programmed consequences were now delivered after each response, or at the end of the 10-s interval if no response occurred. In other words, objectaction relations (A1-wave and A2-clap) were explicitly trained. Note however, that no instructions were provided (i.e., the child was not told what to do at the beginning of a trial). This constituted the first exemplar in symmetry training. Eight consecutively correct trials were required to complete this phase. 
Session II. The procedures outlined in Phases 1, 2, 3, and 4 of Session I were repeated, but novel stimuli and actions, and their respective names were employed. Waving was replaced by Arms Out and clapping was replaced by Arms In. A1 was replaced by B1 (e.g., storybook) and A2 was replaced by B2 (e.g., flower) (see Tables $2 \& 3$ ). Thus, the action-object relations Arms Out-B1 and Arms In-B2 were trained explicitly in Phase 2. After retraining for naming in Phase 3, the derived object-action relations (B1-Arms Out and B2-Arms In) were tested in Phase 4. If a subject achieved eight consecutively correct trials in the symmetry test in Phase 4 of Session II, her/his participation in the experiment was terminated for the time being. At this point in the experiment, the multiple-baseline design required that Subjects 3 and 4 be immediately reexposed to Phase 2 (i.e., the action-object training) before proceeding to the next session. If Subjects 1 and/or 2 failed the test, however, they were exposed immediately to Phase 5 (symmetry training).

Table 3

Stimulus Labels, and Trained and Tested Relations Employed in Each Session of Each of 4 Experiments

\begin{tabular}{cll}
\hline Session No. & Trained Action-Object Relations & Tested Object-Action Relations \\
\hline I & Wave-A1 \& Clap-A2 & A1-Wave \& A2-Clap \\
II & Arms Out-B1 \& Arms In-B2 & B1-Arms Out \& B2-Arms In \\
III & Pulling Ear-C1 \& Pulling Nose-C2 & C1-Pulling Ear \& C2-Pulling Nose \\
IV & Rubbing Head-D1 \& Scratching Tummy-D2 & D1-Rubbing Head \& D2-Scratching Tummy \\
V & Touching Feet-E1 \& Flapping Arms-E2 & E1-Touching Feet \& E2-Flapping Arms \\
VI & Hands Behind Back-F1 \& Hands Over Eyes-F2 & F1-Hands Behind Back \& F2-Hands Over Eyes \\
(Follow-up) & & \\
\hline
\end{tabular}

Session III. The procedures outlined in Phases 1, 2, 3, and 4 of Sessions I and II were repeated, but Arms Out was replaced by Pulling Ear and Arms In was replaced by Pulling Nose. B1 was replaced by C1 (e.g., toy bear) and B2 was replaced by $\mathrm{C} 2$ (e.g., toy building block). Thus, the actionobject relations Pulling Ear-C1 and Pulling Nose-C2 were trained explicitly in Phase 2, and C1-Pulling Ear and C2-Pulling Nose were tested in Phase 4. If a subject achieved eight consecutively correct trials in the symmetry test in Phase 4 of Session III, her/his participation in the experiment was terminated for the time being. At this point, in the experiment the multiplebaseline design required that Subject 4 be immediately reexposed to Phase 2 (i.e., the action-object training) before proceeding to the next session. If Subjects 1, 2, and/or 3 failed the test, however, they were exposed immediately to Phase 5 (symmetry training).

Session IV. Session IV was identical to Session III, but novel stimuli and actions, and their respective names, were employed. The actionobject relations Rubbing Head-D1 (e.g., cup) and Scratching Tummy-D2 (e.g., shoe) were trained explicitly, and the object-action relations D1Rubbing Head and D2-Scratching Tummy were tested. If a subject passed the symmetry test, her/his participation in the experiment was terminated for the time being. The multiple-baseline design required that 
Subject 4 be exposed immediately to Phase 5 (explicit symmetry training), before proceeding to the next session. If Subjects 1,2 , and/or 3 failed the test, they were also exposed immediately to Phase 5 (symmetry training). At this point in the experiment, therefore, no subjects were reexposed to Phase 2.

Session V. Phases 1, 2, 3, and 4 were repeated, but novel stimuli and actions, and their respective names, were employed. The action-object relations Touching Feet-E1 (e.g., pencil) and Flapping Arms-E2 (e.g., bag) were trained explicitly, and E1-Touching Feet and E2-Flapping Arms were tested. Session V did not contain Phase 5.

Session VI (2-month follow-up). Two of the subjects were available to participate in the Follow-Up Session. This was identical to Session V, but novel stimuli and actions, and their respective names, were employed. The action-object relations Hands Behind Back-F1 (e.g., hat) and Hands Over Eyes-F2 (e.g., plate) were trained explicitly, and F1-Hands Behind Back and F2-Hands Over Eyes were tested. This was the end of Experiment 1.

\section{Results}

The data from Experiment 1 are presented in Table 4. Only 1 subject (1) demonstrated derived symmetry (i.e., object-action relations) without first receiving explicit symmetry training. The remaining 3 subjects showed derived symmetry only after explicit symmetry training. A detailed description of the data for these 3 subjects is provided below.

\section{Subject 2}

Subject 2 completed the name training with waving and clapping and A1 and A2 in 24 trials (i.e., 2 blocks of 12 trials). The conditional discrimination training of the action-object relations was completed in 16 trials. On name retraining, she produced 12 out of 12 consecutively correct naming responses. Subsequently, Subject 2 was tested for the derivation of object-action relations, but failed to pass, producing only 5 correct responses. She was then reexposed to the conditional discrimination (action-object) training with the stimuli employed in Session I.

In Session II, Subject 2 successfully demonstrated naming of novel actions and novel objects in 24 trials. Training of the new action-object relations was completed in a total of 9 trials, after which she produced 12 consecutively correct responses during name retraining. She was then tested (for the second time) for the derivation of the novel object-action relations and again failed by producing 4 correct responses. At this point, Subject 2 was exposed to explicit symmetry (object-action) training for the first time involving the stimuli employed in Session II. She completed this object-action training in only 9 trials.

Subject 2 began Session III using another novel set of actions and objects. She completed the name training in 24 trials. She required 11 trials of conditional discrimination training and completed the name 
Table 4

Training Trials and Correct Responses During Test Trials for Each Subject in Experiment 1

\begin{tabular}{|c|c|c|c|c|}
\hline Subjects & 1 & 2 & 3 & 4 \\
\hline $\begin{array}{l}\text { Session I } \\
\text { Ph. } 1 \text { - Name training: } \\
\text { Ph. } 2 \text { - Action-object training: } \\
\text { Ph. } 3 \text { - Name retraining: } \\
\text { Ph. } 4 \text { - Test derived object-action: } \\
\text { Ph. } 5 \text { - Object-action training: }\end{array}$ & $\begin{array}{l}24 \\
14 \\
12 \\
8 / 8 \\
-\end{array}$ & $\begin{array}{r}24 \\
16 \\
12 \\
5 / 8 \\
-{ }^{\star}\end{array}$ & $\begin{array}{r}24 \\
9 \\
12 \\
1 / 8 \\
-{ }^{*}\end{array}$ & $\begin{array}{r}12 \\
10 \\
12 \\
6 / 8 \\
-^{*}\end{array}$ \\
\hline $\begin{array}{l}\text { Session II } \\
\text { Ph. } 1 \text { - Name training: } \\
\text { Ph. } 2 \text { - Action-object training: } \\
\text { Ph. } 3 \text { - Name retraining: } \\
\text { Ph. } 4 \text { - Test derived object-action: } \\
\text { Ph. } 5 \text { - Object-action training: }\end{array}$ & $\begin{array}{l}- \\
- \\
-\end{array}$ & $\begin{array}{r}24 \\
9 \\
12 \\
4 / 8 \\
9\end{array}$ & $\begin{array}{r}24 \\
11 \\
12 \\
5 / 8 \\
-^{*}\end{array}$ & $\begin{array}{r}24 \\
10 \\
12 \\
4 / 8 \\
-*\end{array}$ \\
\hline $\begin{array}{l}\text { Session III } \\
\text { Ph. } 1 \text { - Name training: } \\
\text { Ph. } 2 \text { - Action-object training: } \\
\text { Ph. } 3 \text { - Name retraining: } \\
\text { Ph. } 4 \text { - Test derived object-action: } \\
\text { Ph. } 5 \text { - Object-action training: }\end{array}$ & $\begin{array}{l}- \\
- \\
-\end{array}$ & $\begin{array}{r}24 \\
11 \\
12 \\
8 / 8 \\
-\end{array}$ & $\begin{array}{r}24 \\
13 \\
12 \\
3 / 8 \\
9\end{array}$ & $\begin{array}{r}12 \\
9 \\
12 \\
0 / 8 \\
-*\end{array}$ \\
\hline $\begin{array}{l}\text { Session IV } \\
\text { Ph. } 1 \text { - Name training: } \\
\text { Ph. } 2 \text { - Action-object training: } \\
\text { Ph. } 3 \text { - Name retraining: } \\
\text { Ph. } 4 \text { - Test derived object-action: } \\
\text { Ph. } 5 \text { - Object-action training: }\end{array}$ & $\begin{array}{l}- \\
- \\
-\end{array}$ & $\begin{array}{l}- \\
- \\
-\end{array}$ & $\begin{array}{r}12 \\
12 \\
24 \\
7 / 8 \\
8\end{array}$ & $\begin{array}{r}12 \\
10 \\
12 \\
3 / 8 \\
9\end{array}$ \\
\hline $\begin{array}{l}\text { Session } \mathrm{V} \\
\mathrm{Ph} .1 \text { - Name training: } \\
\mathrm{Ph} .2 \text { - Action-object training: } \\
\mathrm{Ph} .3 \text { - Name retraining: } \\
\mathrm{Ph} .4 \text { - Test derived object-action: }\end{array}$ & $\frac{-}{-}$ & $\frac{-}{-}$ & $\begin{array}{r}12 \\
10 \\
12 \\
8 / 8\end{array}$ & $\begin{array}{r}12 \\
9 \\
12 \\
8 / 8\end{array}$ \\
\hline $\begin{array}{l}\text { Session VI (2-Month Follow-Up) } \\
\text { Ph. } 1 \text { - Name training: } \\
\text { Ph. } 2 \text { - Action-object training: } \\
\mathrm{Ph} .3 \text { - Name retraining: } \\
\mathrm{Ph} .4 \text { - Test derived object-action: }\end{array}$ & $\begin{array}{l}- \\
-\end{array}$ & $\begin{array}{r}12 \\
12 \\
12 \\
8 / 8\end{array}$ & $\frac{-}{-}$ & $\begin{array}{r}24 \\
11 \\
12 \\
8 / 8\end{array}$ \\
\hline
\end{tabular}

* Indicates that the subject was reexposed to action-object training. In all cases, subjects completed the training in eight trials (i.e., the minimum number required).

retraining in the minimum number of trials. She then immediately passed the test for derived object-action symmetry, producing no errors. Subject 2 did not, therefore, require Sessions IV and V. Two months later, she was exposed to the Follow-up Session involving a new set of actions and objects. In this session she passed the name training in the minimum number of trials. She required 12 trials to complete the conditional discrimination training, and then passed the name retraining in the minimum number of trials. She immediately passed the test for the transformation of function in accordance with symmetry without error. 


\section{Subject 4}

Subject 4 completed the name training in the minimum number of trials in Session I. He required only 10 trials to complete the action-object training. He produced no errors on name retraining. Subsequently, Subject 4 failed the test for the derivation of object-action relations by producing 6 correct responses. He was then reexposed to the conditional discrimination training with the stimuli employed in Session I.

In Session II, Subject 4 successfully demonstrated naming of novel actions and novel objects in 24 trials. He required 10 trials to complete the new action-object training, after which he produced no errors on the name retraining. He was then tested (for the second time) for the derivation of the novel object-action relations and his performance deteriorated to only 4 correct responses. At this point, Subject 4 was reexposed to the conditional discrimination training with the stimuli employed in Session II.

In Session III, Subject 4 produced no errors on the novel name training. He required only 9 trials to complete the new action-object conditional discriminations, and produced no errors on the name retraining. On the (third) test for derived object-action relations, the performance of this subject deteriorated again, and he now produced no correct responses. After this test, he was again reexposed to the conditional discrimination training involving the stimuli and actions employed in Session III.

In Session IV, he produced no errors in the name training with a novel set of actions and objects. He required only 10 trials to complete the new action-object training, and he produced no errors on the name retraining. $\mathrm{He}$ again failed the test for derived object-action relations, by producing only 3 correct responses. At this point, after three failures on the transformation of function test, and four sessions of name, and conditional discrimination training, he was exposed to the first exemplar of explicit symmetry training, which he completed in 9 trials.

In the subsequent session (V), he produced perfect responding on the name training involving a novel set of actions and objects. He completed the new conditional discrimination training in 9 trials, and he made no errors on the name retraining. He immediately passed the transformation of function test with no errors. Two months later, he was exposed to the Follow-up Session involving a new set of actions and objects. In this session he required 24 trials to complete the name training. He completed the novel action-object training in 11 trials, after which he passed the name retraining without error. $\mathrm{He}$ immediately passed the test for the transformation of function in accordance with symmetry by producing no errors.

\section{Subject 3}

The performance of Subject 3 was similar to that produced by Subjects 2 and 4 , with one minor difference. After one exemplar of explicit symmetry training in Session III, Subject 3 proceeded to Session IV involving a new set of actions and objects. On the test for derived object- 
action relations, this subject narrowly missed the pass criterion by producing 1 error. He was then immediately reexposed to another exemplar of explicit symmetry training involving the same stimuli employed in Session IV. In Session V, he subsequently passed the test for derived object-actions relations without error.

\section{Discussion}

Only 1 of the 4 children involved in this experiment passed the initial test for the derived transformation of function in accordance with symmetry. For the 3 subjects who failed, a multiple-baseline design was employed which staggered the introduction of explicit symmetry training. All subjects passed the transformation of function test after one or two exemplars of explicit symmetry training. One subject (4), who had four sessions of name, and conditional discrimination training, failed to demonstrate derived transformation of function, but immediately did so after only one exemplar of symmetry training. The results of this multiplebaseline experiment provide strong evidence that explicit training in symmetry responding is a powerful method for establishing derived symmetry within the context of the current procedure.

One possible criticism of Experiment 1 might be that the name retraining hindered the emergence of symmetry, because this retraining was placed between the conditional discrimination training and the symmetry test. For example, perhaps the stimulus control established during the name retraining competed in some undefined way with the previously trained conditional discriminations. If this was the case, then removing the name retraining should improve test performances before the introduction of explicit symmetry training. Experiment 2 tested this suggestion.

\section{Experiment 2}

\section{Procedure}

Experiment 2 replicated Experiment 1, with some minor modifications. The name retraining was omitted, and subjects were required to produce 24 (i.e., 2 blocks of 12) consecutively correct responses during the name training (i.e., in Phase 1). All other aspects of the procedure were the same.

\section{Results and Discussion}

The data from Experiment 2 are presented in Table 5. None of the subjects in this experiment passed the first symmetry test. Overall, the patterns of responding were similar to those observed in the previous experiment, in that all 4 subjects showed derived symmetry only after explicit symmetry training. Subject 7 was the only subject who required two separate exposures to this explicit training (note, however, that this subject failed the first exposure by only one incorrect response). The 2 
subjects $(7 \& 8)$ who were available for the Follow-up Session replicated their earlier successful performances on the symmetry test. These data therefore indicate that the name retraining was not responsible for the subjects' failures on the symmetry tests observed in Experiment 1.

Table 5

Training Trials and Correct Responses During Test Trials for Each Subject in Experiment 2

\begin{tabular}{|c|c|c|c|c|}
\hline Subjects & 5 & 6 & 7 & 8 \\
\hline $\begin{array}{l}\text { Session I } \\
\text { Ph. } 1 \text { - Name training: } \\
\text { Ph. } 2 \text { - Action-object training: } \\
\text { Ph. } 3 \text { - Test derived object-action: } \\
\text { Ph. } 4 \text { - Object-action training: }\end{array}$ & $\begin{array}{l}36 \\
12 \\
6 / 8 \\
8\end{array}$ & $\begin{array}{l}36 \\
11 \\
6 / 8 \\
{ }^{*}\end{array}$ & $\begin{array}{l}36 \\
16 \\
2 / 8 \\
\text { - }^{*}\end{array}$ & $\begin{array}{l}48 \\
11 \\
5 / 8 \\
-{ }^{*}\end{array}$ \\
\hline $\begin{array}{l}\text { Session II } \\
\text { Ph. } 1 \text { - Name training: } \\
\text { Ph. } 2 \text { - Action-object training: } \\
\text { Ph. } 3 \text { - Test derived object-action: } \\
\text { Ph. } 4 \text { - Object-action training: }\end{array}$ & $\begin{array}{l}36 \\
9 \\
8 / 8 \\
-\end{array}$ & $\begin{array}{l}36 \\
11 \\
4 / 8 \\
11\end{array}$ & $\begin{array}{l}48 \\
16 \\
0 / 8 \\
-{ }^{*}\end{array}$ & $\begin{array}{l}36 \\
12 \\
7 / 8 \\
-\end{array}$ \\
\hline $\begin{array}{l}\text { Session III } \\
\text { Ph. } 1 \text { - Name training: } \\
\text { Ph. } 2 \text { - Action-object training: } \\
\text { Ph. } 3 \text { - Test derived object-action: } \\
\text { Ph. } 4 \text { - Object-action training: }\end{array}$ & $\begin{array}{l}- \\
- \\
-\end{array}$ & $\begin{array}{l}36 \\
10 \\
8 / 8 \\
-\end{array}$ & $\begin{array}{l}48 \\
19 \\
2 / 8 \\
32\end{array}$ & $\begin{array}{l}36 \\
10 \\
3 / 8 \\
-^{\star}\end{array}$ \\
\hline $\begin{array}{l}\text { Session IV } \\
\text { Ph. } 1 \text { - Name training: } \\
\text { Ph. } 2 \text { - Action-object training: } \\
\text { Ph. } 3 \text { - Test derived object-action: } \\
\text { Ph. } 4 \text { - Object-action training: }\end{array}$ & $\begin{array}{l}- \\
- \\
-\end{array}$ & $\begin{array}{l}- \\
- \\
-\end{array}$ & $\begin{array}{l}48 \\
18 \\
7 / 8 \\
11\end{array}$ & $\begin{array}{l}36 \\
9 \\
2 / 8 \\
9\end{array}$ \\
\hline $\begin{array}{l}\text { Session V } \\
\text { Ph. } 1 \text { - Name training: } \\
\text { Ph. } 2 \text { - Action-object training: } \\
\text { Ph. } 3 \text { - Test derived object-action: }\end{array}$ & $\overline{-}$ & $\bar{z}$ & $\begin{array}{l}36 \\
16 \\
8 / 8\end{array}$ & $\begin{array}{l}36 \\
11 \\
8 / 8\end{array}$ \\
\hline $\begin{array}{l}\text { Session VI (2-Month Follow-Up) } \\
\text { Ph. } 1 \text { - Name training: } \\
\text { Ph. } 2 \text { - Action-object training: } \\
\text { Ph. } 3 \text { - Test derived object-action: }\end{array}$ & Z & $\frac{-}{-}$ & $\begin{array}{l}36 \\
14 \\
8 / 8\end{array}$ & $\begin{array}{l}24 \\
12 \\
8 / 8\end{array}$ \\
\hline
\end{tabular}

Note. * Indicates that the subject was reexposed to action-object training. In all cases, subjects completed the training in eight trials (i.e., the minimum number required.)

One criticism of the two previous experiments might be that the children were not required to engage in any naming behaviors during the action-object training or during the object-action symmetry test. Perhaps, if subjects were provided with the name training, and were required to tact (i.e., discriminate) the actions and objects during the training and testing trials, this might facilitate derived symmetry responding in the absence of explicit symmetry training (see Dugdale \& Lowe, 1990; Eikeseth \& Smith, 1992). To address this concern, Experiment 3 was conducted.

Procedure

\section{Experiment 3}

Experiment 3 replicated Experiment 1, except that subjects were required 
to tact the stimuli and actions on all conditional discrimination training and symmetry test trials. During a training trial, the experimenter may have waved at the child, for example, whilst asking "What am I doing?". After the tacting response, the child was asked to pick one of the two objects presented as comparisons (e.g., the doll), and then tact that chosen comparison. Feedback contingent on comparison choice (but not naming) was then presented. During a test trial, the experimenter may have placed the doll, for example, in front of the child and asked "What's this?". After the child tacted the object, the experimenter waited in silence for $10 \mathrm{~s}$ for the child to emit an action. If and when the child emitted an action, the experimenter asked, "What are you doing," and when the child tacted the action, that completed the test trial. All tacting responses were recorded, but no corrective feedback was provided for this naming behavior on either training or test trials. No tacting errors were produced by any of the 4 children during training or testing.

\section{Results and Discussion}

The data from Experiment 3 are presented in Table 6 and are remarkably similar to those from the previous experiments. Only 1 subject (11) passed the first symmetry test. The other 3 subjects demonstrated derived symmetry only after explicit symmetry training, despite the fact that they successfully tacted the objects and actions on all conditional discrimination training and testing trials. In addition, subjects in this experiment required approximately the same number of conditional discrimination training trials as previous subjects, although they successfully tacted the actions and objects during the training. Finally, the follow-up data taken from 2 of the subjects $(9 \& 10)$ indicated that derived symmetry responding remained in the children's repertoires. These results provide yet further evidence that explicit symmetry training is a powerful method for generating derived symmetry.

Another possible question that arose at this point in the research program was whether a different pattern of responding would emerge if we directly trained object-action relations in the conditional discrimination training, and then tested for the derivation of action-object relations (i.e., reverse the trained and tested relations). The literature on cross-modal generalization, from receptive to expressive language and vice versa, suggests that the direction in which subjects are trained and tested in such verbal skills has an effect on performance. For example, a study by Smeets and Striefel (1976) demonstrated that for a deaf mentally retarded woman, training of expressive signs produced transfer to receptive signing, but there was not always transfer from receptive to expressive signing. Although, there have also been arguments to the contrary (Grant \& Evans, 1994), we felt that it was important at this stage to examine the possible effects of reversing the direction of training and testing within our experimental protocol. Our concern for this issue arose from the idea that action-object relations may be functionally similar to receptive signing, whereas the object-action relations may be functionally similar to expressive signing. Experiment 4 was designed to address this issue. 
Table 6

Training Trials and Correct Responses During Test Trials for Each Subject in Experiment 3

\begin{tabular}{|c|c|c|c|c|}
\hline Subjects & 9 & 10 & 11 & 12 \\
\hline $\begin{array}{l}\text { Session I } \\
\text { Ph. } 1 \text { - Name training: } \\
\text { Ph. } 2 \text { - Action-object training: } \\
\text { Ph. } 3 \text { - Name retraining: } \\
\text { Ph. } 4 \text { - Test derived object-action: } \\
\text { Ph. } 5 \text { - Object-action training: }\end{array}$ & $\begin{array}{r}12 \\
20 \\
12 \\
3 / 8 \\
9\end{array}$ & $\begin{array}{l}24 \\
18 \\
24 \\
6 / 8 \\
-\end{array}$ & $\begin{array}{l}24 \\
17 \\
12 \\
8 / 8 \\
-\end{array}$ & $\begin{array}{l}12 \\
12 \\
12 \\
5 / 8 \\
-\star\end{array}$ \\
\hline $\begin{array}{l}\text { Session II } \\
\text { Ph. } 1 \text { - Name training: } \\
\text { Ph. } 2 \text { - Action-object training: } \\
\text { Ph. } 3 \text { - Name retraining: } \\
\text { Ph. } 4 \text { - Test derived object-action: } \\
\text { Ph. } 5 \text { - Object-action training: }\end{array}$ & $\begin{array}{r}24 \\
10 \\
12 \\
8 / 8 \\
-\end{array}$ & $\begin{array}{r}12 \\
9 \\
12 \\
4 / 8 \\
9\end{array}$ & $\begin{array}{l}- \\
- \\
-\end{array}$ & $\begin{array}{l}24 \\
13 \\
12 \\
3 / 8 \\
-\end{array}$ \\
\hline $\begin{array}{l}\text { Session III } \\
\text { Ph. } 1 \text { - Name training: } \\
\text { Ph. } 2 \text { - Action-object training: } \\
\text { Ph. } 3 \text { - Name retraining: } \\
\text { Ph. } 4 \text { - Test derived object-action: } \\
\text { Ph. } 5 \text { - Object-action training: }\end{array}$ & $\begin{array}{l}\overline{-} \\
\overline{-} \\
-\end{array}$ & $\begin{array}{r}24 \\
11 \\
12 \\
8 / 8 \\
-\end{array}$ & $\begin{array}{l}- \\
- \\
-\end{array}$ & $\begin{array}{l}24 \\
12 \\
12 \\
4 / 8 \\
\mathbf{-}^{*}\end{array}$ \\
\hline $\begin{array}{l}\text { Session IV } \\
\text { Ph. } 1 \text { - Name training: } \\
\text { Ph. } 2 \text { - Action-object training: } \\
\text { Ph. } 3 \text { - Name retraining: } \\
\text { Ph. } 4 \text { - Test derived object-action: } \\
\text { Ph. } 5 \text { - Object-action training: }\end{array}$ & $\begin{array}{l}\overline{-} \\
\overline{-} \\
-\end{array}$ & $\begin{array}{l}\overline{-} \\
z \\
-\end{array}$ & $\begin{array}{l}\overline{-} \\
\overline{-} \\
-\end{array}$ & $\begin{array}{l}12 \\
10 \\
12 \\
3 / 8 \\
11\end{array}$ \\
\hline $\begin{array}{l}\text { Session V } \\
\text { Ph. } 1 \text { - Name training: } \\
\text { Ph. } 2 \text { - Action-object training: } \\
\text { Ph. } 3 \text { - Name retraining: } \\
\text { Ph. } 4 \text { - Test derived object-action: }\end{array}$ & $\begin{array}{l}- \\
-\end{array}$ & $\begin{array}{c}- \\
-\end{array}$ & $\frac{-}{-}$ & $\begin{array}{l}12 \\
10 \\
12 \\
8 / 8\end{array}$ \\
\hline $\begin{array}{l}\text { Session VI (2-Month Follow-Up) } \\
\text { Ph. } 1 \text { - Name training: } \\
\text { Ph. } 2 \text { - Action-object training: } \\
\text { Ph. } 3 \text { - Name retraining: } \\
\text { Ph. } 4 \text { - Test derived object-action: }\end{array}$ & $\begin{array}{r}12 \\
10 \\
12 \\
8 / 8\end{array}$ & $\begin{array}{r}14 \\
12 \\
12 \\
8 / 8\end{array}$ & $\frac{-}{-}$ & $\begin{array}{l}- \\
- \\
-\end{array}$ \\
\hline
\end{tabular}

Note. * Indicates that the subject was reexposed to action-object training. In all cases, subjects completed the training in eight trials (i.e., the minimum number required).

\section{Experiment 4}

\section{Procedure}

Experiment 4 replicated Experiment 1, except that the trained and tested relations were reversed. In effect, we now trained object-action relations and tested for action-object relations. On the first training trial, the experimenter presented a doll, for example, and said "When I show you this, I want you to either clap or wave. I will tell you if you have done the right or wrong thing." The appropriate programmed consequences followed all training trials. The same procedure was used for all 
subsequent training trials, except that the verbal instruction was omitted after the first four trials. During all action-object test trials, the experimenter placed two objects (e.g., A1 and A2) horizontally across the table from one another, looked down at the near edge of the table (i.e., the subject could not see the experimenter's face), emitted one of two actions (e.g., clapping or waving), and then waited for $10 \mathrm{~s}$. If the subject picked one of the two objects, or failed to emit a choice response within $10 \mathrm{~s}$ (in fact, this never occurred), the experimenter removed the objects from the table, before commencing the next test trial. During action-object test trials, no programmed consequences were presented, but during explicit symmetry training, the appropriate programmed consequences followed these trials.

\section{Results and Discussion}

The data from Experiment 4 are presented in Table 7. One subject (16) passed the first object-action symmetry test (i.e., without explicit

Table 7

Training Trials and Correct Responses During Test Trials for Each Subject in Experiment 4

\begin{tabular}{|c|c|c|c|c|}
\hline Subjects & 13 & 14 & 15 & 16 \\
\hline $\begin{array}{l}\text { Session I } \\
\text { Ph. } 1 \text { - Name training: } \\
\text { Ph. } 2 \text { - Object-action training: } \\
\text { Ph. } 3 \text { - Name retraining: } \\
\text { Ph. } 4 \text { - Test derived action-object: } \\
\text { Ph. } 5 \text { - Action-object training: }\end{array}$ & $\begin{array}{r}24 \\
22 \\
24 \\
5 / 8 \\
9\end{array}$ & $\begin{array}{r}12 \\
12 \\
12 \\
2 / 8 \\
-\end{array}$ & $\begin{array}{r}24 \\
19 \\
12 \\
1 / 8 \\
-\end{array}$ & $\begin{array}{l}24 \\
11 \\
12 \\
8 / 8 \\
-\end{array}$ \\
\hline $\begin{array}{l}\text { Session II } \\
\text { Ph. } 1 \text { - Name training: } \\
\text { Ph. } 2 \text { - Object-action training: } \\
\text { Ph. } 3 \text { - Name retraining: } \\
\text { Ph. } 4 \text { - Test derived action-object: } \\
\text { Ph. } 5 \text { - Action-object training: }\end{array}$ & $\begin{array}{r}12 \\
11 \\
24 \\
8 / 8 \\
-\end{array}$ & $\begin{array}{r}24 \\
9 \\
12 \\
6 / 8 \\
8\end{array}$ & $\begin{array}{r}12 \\
9 \\
12 \\
3 / 8 \\
-^{*}\end{array}$ & $\begin{array}{l}\bar{z} \\
\bar{z} \\
\overline{-}\end{array}$ \\
\hline $\begin{array}{l}\text { Session III } \\
\text { Ph. } 1 \text { - Name training: } \\
\text { Ph. } 2 \text { - Object-action training: } \\
\text { Ph. } 3 \text { - Name retraining: } \\
\text { Ph. } 4 \text { - Test derived action-object: } \\
\text { Ph. } 5 \text { - Action-object training: }\end{array}$ & $\begin{array}{l}- \\
- \\
-\end{array}$ & $\begin{array}{r}24 \\
12 \\
12 \\
8 / 8 \\
-\end{array}$ & $\begin{array}{r}12 \\
9 \\
12 \\
5 / 8 \\
11\end{array}$ & $\begin{array}{l}- \\
\overline{-} \\
-\end{array}$ \\
\hline $\begin{array}{l}\text { Session IV } \\
\text { Ph. } 1 \text { - Name training: } \\
\text { Ph. } 2 \text { - Object-action training: } \\
\text { Ph. } 3 \text { - Name retraining: } \\
\text { Ph. } 4 \text { - Test derived action-object: }\end{array}$ & $\begin{array}{l}- \\
- \\
-\end{array}$ & $\begin{array}{l}- \\
- \\
-\end{array}$ & $\begin{array}{r}24 \\
10 \\
12 \\
8 / 8\end{array}$ & $\begin{array}{l}- \\
- \\
-\end{array}$ \\
\hline $\begin{array}{l}\text { Session V (2-Month Follow-Up) } \\
\text { Ph. } 1 \text { - Name training: } \\
\text { Ph. } 2 \text { - Object-action training: } \\
\text { Ph. } 3 \text { - Name retraining: } \\
\text { Ph. } 4 \text { - Test derived action-object: }\end{array}$ & $\begin{array}{l}- \\
- \\
-\end{array}$ & $\begin{array}{r}24 \\
12 \\
12 \\
8 / 8\end{array}$ & $\begin{array}{r}12 \\
9 \\
12 \\
8 / 8\end{array}$ & $\begin{array}{l}- \\
- \\
-\end{array}$ \\
\hline
\end{tabular}

Note. * Indicates that the subject was reexposed to object-action training. In all cases, subjects completed the training in eight trials (i.e., the minimum number required.) 
symmetry training). The patterns of responding emitted by the other 3 subjects were consistent with the previous experiments in that all 3 showed derived symmetry only after explicit symmetry training. All 3 subjects received only one exemplar of explicit symmetry training before passing the test. Follow-up data from 2 subjects $(14 \& 15)$ indicated that deriving symmetry was stable across time. The results of this experiment indicate that reversing the direction of trained and tested relations did not affect the subjects' test performances.

\section{GENERAL DISCUSSION}

The main purpose of the present study was to determine whether exemplar training would facilitate the transformation of function in accordance with symmetry, in the context of an action-object relations task. Experiments 1, 2, and 3 clearly showed that explicit symmetry training across one or two exemplars was extremely effective in this regard. Experiment 4 produced similar results when the trained and tested relations were reversed. In summary, Experiments 1 to 4 repeatedly showed that symmetry training across one or two exemplars was extremely effective in establishing derived symmetry responding. The multiple-baseline design employed in each of the experiments allows us to be reasonably confident that the exemplar training was the effective variable in this study. Furthermore, follow-up data across all four experiments indicated that the repertoires of derived symmetry responding, established in the context of the current procedures, remained stable across time. Relational frame theory predicts that exemplar training should be a powerful method for facilitating a derived transformation of functions in accordance with symmetry, and the current data therefore appear to support this view.

An interesting feature of the data from all of the experiments is that only one or two exemplars of explicit symmetry training were required before subjects showed symmetry on a subsequent set of actions and objects. These findings contrast with those reported by Schusterman and Kastak (1993) in which many exemplars were used to establish derived stimulus relations in a sea lion. The limited number of exemplars needed in the current study could be taken to indicate that the exemplar training was in some way discriminative for an already established behavioral repertoire (i.e., bidirectional stimulus relations were not established for the first time in the current study). This interpretation is entirely consistent with the aims of the current research. As indicated in the introduction, we deliberately avoided using a traditional matching-to-sample preparation for both training and testing, because this procedure likely possesses contextual cues for symmetry responding. The current procedure clearly did not possess these cues, and thus it allowed us to examine systematically the effectiveness of exemplar training in generating derived symmetry in the context of the current experimental preparation. From the perspective of RFT, therefore, the current study almost certainly 
did not establish a repertoire of symmetry responding ab initio (much younger children would be required for this purpose), but the exemplar training did establish the experimental context as a cue for producing the preexperimentally established repertoire of symmetry responding. One interesting implication of this RFT interpretation is that it may be possible to facilitate symmetry in the context of the current experimental procedures with means other than explicit symmetry training. For example, perhaps for some children the explicit symmetry training established the procedure as a cue for symmetry simply by providing a history of reinforcement for responding on a task that was formally similar to one that was used during testing. More informally, the children may not have realized that they were required to emit one of two actions when presented with an object, for example, until after they had received the explicit symmetry training. Indeed, the fact that the experimenter did not face the subject during test trials (i.e., she looked down at the edge of the table) may have increased the ambiguity of the task. If this was the case, however, then one would expect a high number of "no-response" errors during the test phases (i.e., because the children did not know what to do). Although no systematic, trial-by-trial record of these errors was kept, the experimenter and independent observer reported that only 3 subjects ever failed to respond, and then on no more than one trial in any given session. Thus it seems likely that most of the children discriminated that one of two previously trained responses was required on each of the test trials.

One might be tempted to view the current data as evidence against the argument that naming mediates, or plays an important role in, derived symmetry responding (e.g., Dugdale \& Lowe, 1990; Eikeseth \& Smith, 1992; Horne \& Lowe, 1996; see Stromer \& McKay, 1996). More specifically, 13 of 16 subjects failed to demonstrate derived symmetry although they had been trained to name all of the relevant actions and objects. Perhaps, however, the name training provided was in some way inappropriate for facilitating symmetry responding. For example, training intraverbal name-sequences (e.g., car-doll-car-doll, etc.) might have been more effective than training listening, echoic, and tacting behaviors for each individual stimulus (see Lowe \& Beasty, 1987). Alternatively, training a common name to the stimuli in each of the designated classes might have proven more successful than training different names (see Dugdale \& Lowe, 1990; Eikeseth \& Smith, 1992). In any case, perhaps a history of naming was necessary for the explicit symmetry training to generate the derived symmetry observed in the present study. Indeed, it could be argued that this history was instrumental in providing the subjects with some form of covert naming strategy (such as intraverbal naming) that was only brought into play after the explicit symmetry training was introduced. Many more studies will be required to address these issues.

One might also argue that the name training employed here might have hindered the derivation of symmetry because the trained names were incongruent with the experimenter-designated classes. Perhaps, for example, a subject incorrectly clapped when presented with a toy car 
because the names "car" and "clap" participated in preexperimentally established relations. Although this may have occurred in some instances, the researchers had no reason to suspect that these types of relations were widely established in the behavioral repertoires of the subjects (e.g., why would the words "clap" and "car" be related more strongly than "clap" and "doll"?). Furthermore, the assignment of objects and actions was randomized across subjects, and thus it is difficult to explain, in terms of incongruent name training, why all but 3 subjects failed to show symmetry before exemplar training in Experiments 1 to 4 . In other words, if previously established relations between the names employed in the study were a powerful determinant of test performance, then surely the random assignment of objects and actions would have, by chance, produced many more successful test performances before the exemplar training was introduced. Finally, if one argues that the previously established name relations hindered symmetry responding, it remains unclear why explicit symmetry training was so effective, even when subjects continued to name the stimuli and actions (e.g., during Experiment 3).The current study was clearly based on RFT, and the data appear to be broadly consistent with this theory. As outlined above, however, the data do not directly contradict naming theory (Horne \& Lowe, 1996). Nevertheless, it would be difficult to argue that our data are consistent with this account. On balance, the data are consistent with accounts other than RFT, such as the Stimulus Control Topography analysis offered by Dube and Mcllvane (1996). At this point, we should stress that it was not our intention to conduct a definitive study that would render one or more theoretical accounts invalid. In fact, we do not believe that such a study will ever be forthcoming (see Barnes, 1994; Barnes \& Roche, 1996). Nevertheless, in due course one of the currently available theoretical accounts may be found to pertain to a broader array of data, or it will suggest a larger number of new and useful empirical investigations. In this regard, we simply note that RFT set the occasion for the present study and others like it (e.g., BarnesHolmes, Barnes-Holmes, \& Roche, in press; Healy, Barnes-Holmes, \& Smeets, 1998; 2000).

The current data suggest that explicit exemplar training (in this case explicit symmetry training) is a reliable means by which to facilitate a derived transformation of function in accordance with symmetry. Now that this effect has clearly been demonstrated, future research is needed to examine the exact way in which exemplar training facilitates the production of symmetry. If the current research helps to stimulate such a program of research, then it will clearly constitute a significant contribution to the investigation of derived relational responding.

\section{References}

BARNES, D. (1994). Stimulus equivalence and relational frame theory. The Psychological Record, 44, 91-124. 
BARNES, D. (1996). Naming as a technical term: Sacrificing behavior analysis at the altar of popularity. Journal of the Experimental Analysis of Behavior, 65, 264-267.

BARNES, D., BROWNE, M., SMEETS, P. M., \& ROCHE, B. (1995). A transfer of functions and a conditional transfer of functions through equivalence relations in three- to six-year-old children. The Psychological Record, 45, 405-430.

BARNES, D., \& HOLMES, Y. (1991). Radical behaviorism, stimulus equivalence, and human cognition. The Psychological Record, 41, 19-31.

BARNES, D., MCCULLAGH, P. D., \& KEENAN, M. (1990). Equivalence class formation in non-hearing impaired children and hearing impaired children. Analysis of Verbal Behavior, 8, 1-11.

BARNES, D., \& ROCHE, B. (1996). Relational frame theory and stimulus equivalence are fundamentally different: A reply to Saunders. The Psychological Record, 46, 236-256.

BARNES-HOLMES, Y., BARNES-HOLMES, D., \& CULLINAN, V. (in press). Education. In S. C. Hayes, D. Barnes-Holmes, \& B. Roche (Eds.), Relational frame theory: A post-Skinnerian account of human language and cognition. New York: Plenum.

DEVANY, J. M., HAYES, S. C., \& NELSON, R. O. (1986). Equivalence class formation in language-able and language-disabled children. Journal of the Experimental Analysis of Behavior, 46, 243-257.

DUBE, W. V., \& MCILVANE, W. J. (1996). Some implications of a stimulus control topography analysis for emergent behavior and stimulus classes. In T. R. Zentall \& P. M. Smeets (Eds.), Stimulus class formation in humans and animals: Advances in Psychology. NL: Elsevier.

DUGDALE, N., \& LOWE, C. F. (1990). Naming and stimulus equivalence. In D. E. Blackman \& H. Lejeune (Eds.), Behavior analysis in theory and practice: Contributions and controversies (pp. 115-138). London: Lawrence Erlbaum Associates.

DYMOND, S., \& BARNES, D. (1995). A transformation of self-discrimination response functions through the arbitrarily applicable relations of sameness, more-than, and less-than. Journal of the Experimental Analysis of Behavior, 64, 163-184.

DYMOND, S., \& BARNES, D. (1996). A transformation of self-discrimination response functions in accordance with the arbitrarily applicable relations of sameness and opposition. The Psychological Record, 46, 271-300.

EIKESETH, S., \& SMITH, T. (1992). The development of functional and equivalence classes in high-functioning autistic children: The role of naming. Journal of the Experimental Analysis of Behavior, 58, 123-133.

GRANT, L., \& EVANS, A. (1994). Principles of behavior analysis. New York: HarperCollins College Publishers.

HAYES, S. C. (1991). A relational control theory of stimulus equivalence. In L. J. Hayes \& P. N. Chase (Eds.), Dialogues on verbal behavior (pp. 109-118). Reno, NV: Context Press.

HAYES, S. C. (1994). Relational frame theory: A functional approach to verbal events. In S. C. Hayes, L. J. Hayes, M. Sato, \& K. Ono (Eds.), Behavior analysis of language and cognition. Reno NV: Context Press.

HAYES, S. C., BARNES-HOLMES, D., \& ROCHE, B. (in press). Relational frame theory: A post-Skinnerian account of human language and cognition. New York: Plenum. 
HAYES, S. C., \& HAYES, L. J. (1989). The verbal action of the listener as the basis for rule-governance. In S. C. Hayes (Ed.), Rule-governed behavior: Cognition, contingencies, and instructional control (pp. 153-190). New York: Plenum Press.

HAYES, S. C., \& HAYES, L. J. (1992). Verbal relations and the evolution of behavior analysis. American Psychologist, 47, 1383-1395.

HEALY, O., BARNES, D., \& SMEETS, P. M., (1998). Derived relational responding as an operant: The effects of between-session feedback. The Psychological Record, 48, 511-536.

HEALY, O., BARNES-HOLMES, D., \& SMEETS, P. M. (2000). Derived relational responding as generalized operant behavior. Journal of the Experimental Analysis of Behavior, 74, 207-227.

HORNE, P. J., \& LOWE, C. F. (1996). On the origins of naming and other symbolic behavior. Journal of the Experimental Analysis of Behavior, 65, 185-241.

LIPKENS, R., HAYES, S. C., \& HAYES, L. J. (1993). Longitudinal study of derived stimulus relations in an infant. Journal of Experimental Child Psychology, $56,201-239$.

LOWE, C. F., \& BEASTY, A. (1987). Language and the emergence of equivalence relations: A developmental study. Bulletin of the British Psychological Society, 40, A49.

ROCHE, B., \& BARNES, D. (1996). Arbitrarily applicable relational responding and human sexual categorization: $A$ critical test of the derived difference relation. The Psychological Record, 46, 451-475.

ROCHE, B., \& BARNES, D. (1997). A transformation of respondently conditioned stimulus function in accordance with arbitrarily applicable relations. Journal of the Experimental Analysis of Behavior, 67, 275-300.

SCHUSTERMAN, R. J., \& KASTAK, D. (1993). A california sea lion is capable of forming equivalence relations. The Psychological Record, 43, 823-840.

SIDMAN, M. (1971). Reading and auditory-visual equivalences. Journal of Speech and Hearing Research, 14, 5-13.

SIDMAN, M. (1994). Equivalence relations and behavior: $A$ research story. Boston: Authors Cooperative.

SMEETS, P. M., BARNES, D., \& LUCIANO, M. C. (1995). Reversal of emergent simple discrimination in children: A component analysis. Journal of Experimental Child Psychology, 60, 327-343.

SMEETS, P. M., \& STRIEFEL, S. (1976). Acquisition and cross-modal generalization of receptive and expressive signing skills in a retarded deaf girl. Journal of Mental Deficiency Research, 20, 251-260.

STEELE, D., \& HAYES, S., C. (1991). Stimulus equivalence and arbitrarily applicable relational responding. Journal of the Experimental Analysis of Behavior, 56, 519-555.

STROMER, R., \& MAKAY, H. A. (1996). Naming and the formation of stimulus classes. In T. R. Zentall \& P. M. Smeets (Eds.), Stimulus class formation in humans and animals (pp. 221-252). Amsterdam, Elsevier Science.

WULFERT, E., \& HAYES, S. C. (1988). Transfer of a conditional ordering response through conditional equivalence classes. Journal of the Experimental Analysis of Behavior, 50, 125-144. 